\title{
Flux and Dose Rate Evaluation of Iter System Using MCNP5
}

\author{
Arione Araújo, Claubia Pereira, Maria Auxiliadora Fortini Veloso, and Antonella Lombardi Costa \\ Departamento de Engenharia Nuclear, Escola de Engenharia, Universidade Federal de Minas Gerais \\ Av. Antônio Carlos 6627 - Prédio do PCA - sala 2299 - Pampulha \\ CEP 31270-010 Belo Horizonte - Minas Gerais - Brasil \\ Hugo Moura Dalle \\ Serviço de Engenharia de Reatores e Sistemas, Centro de Desenvolvimento da Tecnologia \\ Nuclear - Comissão Nacional de Energia Nuclear Av. Antônio Carlos 6627 - Pampulha \\ CEP 31270-010 Belo Horizonte - Minas Gerais - Brasil
}

(Received on 18 November, 2009)

\begin{abstract}
The International Thermonuclear Experimental Reactor (ITER) will perform Deuterium-Tritium (DT) plasma experiments and the neutrons production rate at $14.1 \mathrm{MeV}$ will achieve the level of $10^{13} \mathrm{n} \cdot \mathrm{cm}^{-2} \cdot \mathrm{s}^{-1}$. In this work, the neutron flux and the dose rate during ITER operation has been calculated using the one-dimensional model of the Monte Carlo code MCNP5 and the FENDL/MC-2.1 nuclear data library. The neutron flux and dose rate associated during normal ITER operation were determined along the radial machine direction. Calculations for two different types of concrete compositions were performed to investigate the impact of the bioshield filling materials on the dose rate estimation. The results show that the dose rate level near to the outer wall of the tokamak hall is close to the allowable limit dose. Taking into account the use of large boron concentration in the biological shield concrete (2.9\% weight fraction), it was obtained a dose rate reduction by one order of magnitude. The dose rate is dominated by the secondary gamma ray. The magnitude of the dose rate on the outside hall of bioshield during normal ITER operation can not be considered low in accordance with the result found in the simulation performed in this work, i.e., $1 \mu S v \cdot h^{-1}$.
\end{abstract}

Keywords: Flux; Dose; ITER; MCNP

\section{INTRODUCTION}

The ITER is a tokamak with elongated plasma and single null poloidal divertor. The nominal inductive operation produces a DT fusion power of $500 \mathrm{MW}$ for a burn length of 400 $\mathrm{s}$, with a pulse repetition period of $1,800 \mathrm{~s}$. The ITER will perform experiments with DT plasma and the neutrons production rate at $14.1 \mathrm{MeV}$ will achieve the level of $10^{13} \mathrm{n} \cdot \mathrm{cm}^{-2} \cdot \mathrm{s}^{-1}$ [1]. The high energy neutron flux generated in the plasma chamber will penetrate the machine. Therefore, for safe operation and facility conservation, it is very important to predict the neutron flux and the dose rate distributions during the ITER operation. In this way, studies of dosimetry and radiation protection associated with fusion reactor operation are essential. Some of such investigations were performed for the tokamak HT-7U [2] and for the ITER [3].

The goal is to obtain knowledge about ITER and simulate it using MCNP5 (Monte Carlo N-particle) [4] and in the future, to study the insertion of a transmutation layer in the system and evaluated its depletion and burnup using MCNPX 2.6.0 (Monte Carlo All-Particle Transport Code System)[9] . Based on references [1, 2 and 3] this work simulates a simplified ITER system and analyses its neutron fluxes and dose rates. The present study evaluates the effectiveness of two different types of concrete shielding composition. Both concrete compositions investigated have basically two important differences from the viewpoint of nuclear protection: the density and boron concentration values. In the calculation, the neutron fluxes and their dose rates were determined for some energy groups, namely:

1. thermal neutrons (up to $1 \mathrm{eV}$ ),

2. epithermal neutrons (from $1 \mathrm{eV}$ up to $100 \mathrm{keV}$ ),

3. high-energy neutrons (100 $\mathrm{keV}$ up to $2 \mathrm{MeV}$ ) and,
4. neutrons that lost energy after some interaction (above $2 \mathrm{MeV})$.

To achieve the goal, the mappings of neutron and photon fluxes were performed and their contributions to the dose rate along the radial direction were defined. Finally the total dose rate was also determined.

To achieve the desired results it was used the MCNP5 (Monte Carlo N-particle) code [4] and FENDL (Fusion Evaluated Nuclear Data Library) data library [5]. For dose rate calculation only the transport of particles emitted by the plasma was considered. The delayed photons from activated materials and the tritium dispersed in the air were not considered in the calculations for this work.

\section{METHODOLOGY}

ITER is a complex and large machine that uses several technologies of last generation and its project has high detail level. However, to the propositions of the present study, that is to obtain knowledge, it was adopted the one-dimensional modeling technique. However, to ensure the reliability of the particles transport it was necessary to specify accurately the composition and thickness of the materials along the radial way.

\subsection{Geometric Model}

The geometric model adopted was basically built using concentric finite cylinders as can be seen in the Fig. 1. The cylindrical surfaces are 24 meters high and they have the same axial alignment. Each region between two successive cylindrical surfaces was filled with the appropriate material in or- 
der to represent the different layers of each component along the radial reactor direction.

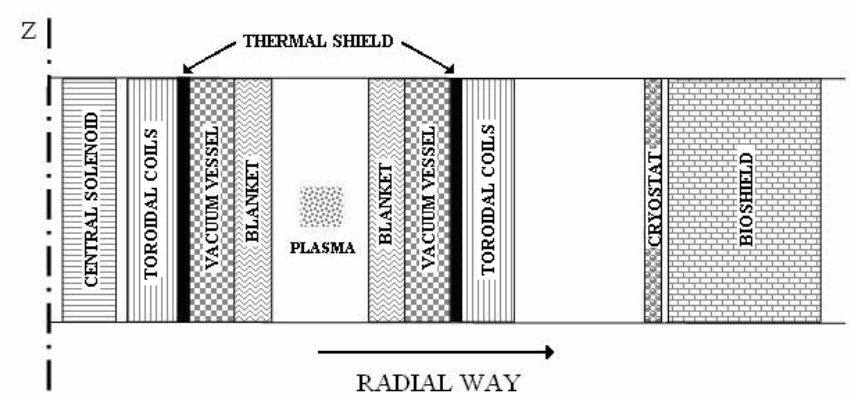

FIG. 1: Radial one-dimensional model profile (scale out). The blank spaces are vacuum areas

This simplified model disregards the detailing of more complex components, omits the vertical and horizontal slits between blanket modules and does not consider components that do not involve the whole machine. The top view of the geometry used in the modeling is shown in the Fig. 2.

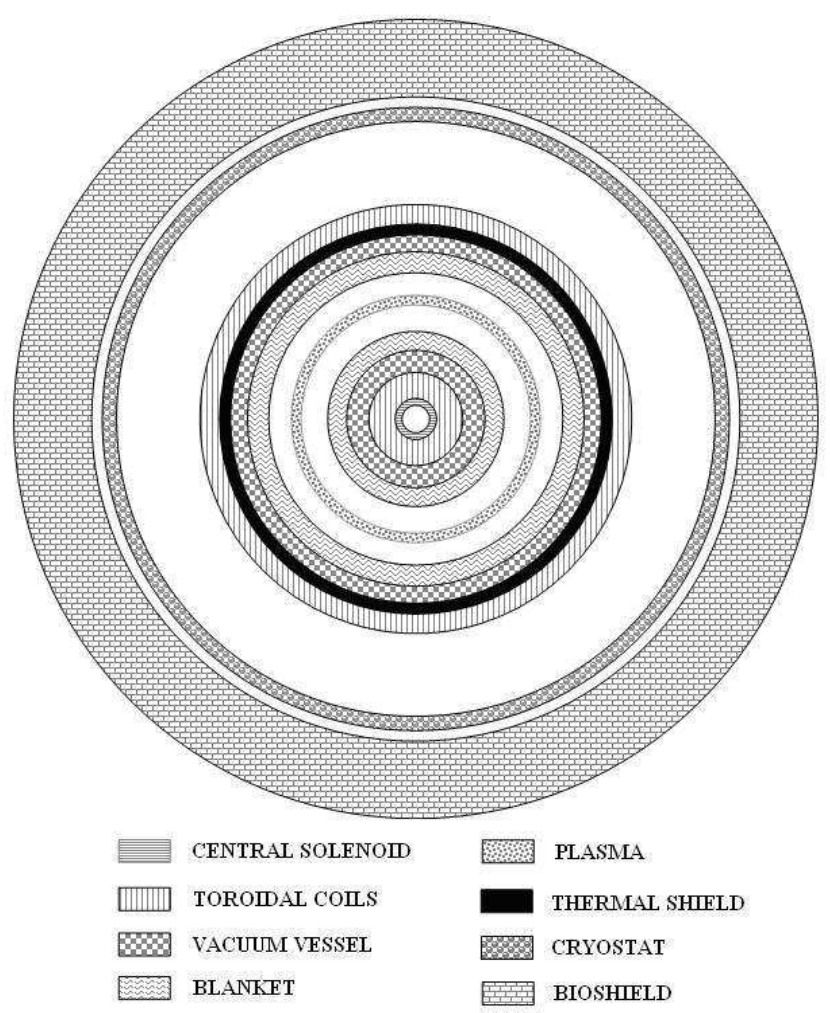

FIG. 2: Top view of geometric model. (scale out). The blank spaces are vacuum areas

\subsection{Materials}

The MCNP code performs the transport of neutrons, photons and electrons, or the combined transport of these particles, where the random path of the particles is simulated on the basis of the stochastic laws with interaction probability inserted from libraries of nuclear cross section. The accuracy obtained with the MCNP simulation depends on several uncertainties involved in the data from nuclear cross sections and also the uncertainty of the statistical calculation. Therefore, the detailing of the material composition for each reactor component is highly relevant to obtain a reliable prediction to the individual history of each neutron in the simulation.

Table 1 presents the reactor systems used in this present study with the thickness and materials for each one of them: central solenoid (CS), blanket (BLK), vacuum vessel (VV), vacuum vessel thermal shield (VVTS), toroidal field coils (TFC), cryostat (CRY) and bioshield (BSD).

In agreement with ITER guidelines [1], 84\% of steel and $16 \%$ of water were used in the filling composition of the blanket shield block. The vacuum vessel was filled with $60 \%$ of steel and $40 \%$ of water. Due to the CS composition complexity, this module was assumed to be composed by $27 \% \mathrm{Nb}_{3} \mathrm{Sn}$ $+30 \%$ Incoloy $908+30 \% \mathrm{SS} 316+10 \%$ resins $+3 \% \mathrm{Al}_{2} \mathrm{O}_{3}$. The small details of the CS composition were not considered in the present model to simplify. The composition of the material filling the CS coils and TF coils was assumed to be $45 \%$ $\mathrm{Nb}_{3} \mathrm{Sn}+50 \%$ Incoloy $908+5 \% \mathrm{Al}_{2} \mathrm{O}_{3}$.

In order to evaluate the effectiveness of shield, the particles transport was conducted for two types of concrete composition for the bioshield. The first concrete type has the typical composition of the Los Alamos concrete (as specified in the MCNP manual) with the following change: $0.07 \%$ of silicium has been replaced by boron. This composition was used by Junker and Weller, 1998 [6]. This first concrete type was called in our study by $\mathrm{C}-01$. The second concrete composition named in our study by C-02 was studied by Khripunovl et al, 1997 [7] and it is considered an alternative to specific shield of fusion plant. The compositions of both types of concrete used in the bioshield are shown in the Table 2.

\subsection{Source}

To simplify, the source used in the simulation emits symmetrically. The neutrons source used is isotropic and has a ring shape with square cross section being $0.60 \mathrm{~m}$ height and $0.60 \mathrm{~m}$ wide, occupying the central part of the plasma chamber. This source does not take in account the plasma emissions asymmetries in the poloidal and toroidal directions. Considering the aims of this study, this simplification is acceptable. The parameters of emission spectrum were adjusted automatically by MCNP through the choice of standard source for DT fusion. The plasma temperature was adjusted for $10 \mathrm{keV}$ [8]. 
Table 1. Material and thickness adopted for the simulated component models

\begin{tabular}{|c|c|c|c|}
\hline \multicolumn{2}{|c|}{ COMPONENT } & THICKNESS $(\mathrm{cm})$ & MATERIAL \\
\hline \multirow{3}{*}{ CS } & Insertion Module & 80 a 90 & $\begin{array}{l}27 \% \mathrm{Nb}_{3} \mathrm{Sn}+30 \% \text { Incoloy } 908+30 \% \\
\mathrm{SS} 316+10 \% \text { resins }+3 \% \mathrm{Al}_{2} \mathrm{O}_{3}\end{array}$ \\
\hline & $\begin{array}{l}\text { Superconductor and } \\
\text { insulator }\end{array}$ & 90 a 180 & $\begin{array}{l}45 \% \mathrm{Nb}_{3} \mathrm{Sn}+5 \% \mathrm{Al}_{2} \mathrm{O}_{3}+50 \% \text { Incoloy } \\
908\end{array}$ \\
\hline & Support & 180 a 200 & SS316L(N)IG \\
\hline \multirow{3}{*}{ TFC } & Wall Box & 220 a 229.5 & SS316L(N)IG \\
\hline & $\begin{array}{l}\text { Superconductor and } \\
\text { insulator }\end{array}$ & 229.5 a 310.5 & $\begin{array}{l}45 \% \mathrm{Nb}_{3} \mathrm{Sn}+5 \% \mathrm{Al}_{2} \mathrm{O}_{3}+50 \% \text { Incoloy } \\
908\end{array}$ \\
\hline & Wall Box & 310.5 a 320 & SS316L(N)IG \\
\hline VVTS & Wall & 320.6 a 322.8 & SS316L(N)IG \\
\hline \multirow{3}{*}{ VV } & Wall & 322.8 a 328.8 & SS316L(N)IG \\
\hline & Filling & 328.8 a 350.5 & $84 \% \mathrm{SS} 316 \mathrm{~L}+16 \% \mathrm{H} 2 \mathrm{O}$ \\
\hline & Wall & 350.5 a 356.5 & SS316L(N)IG \\
\hline \multirow{3}{*}{ BLK } & Shield Block & 357 a 399 & $60 \%$ SS304B $7+40 \% \mathrm{H} 2 \mathrm{O}$ \\
\hline & Waster Heat & 399 a 401 & Copper \\
\hline & First Wall & 401 a 402 & Beryllium \\
\hline \multicolumn{2}{|c|}{ Plasma Chamber } & 402 a 853 & Vacuum \\
\hline \multirow{3}{*}{ BLK } & First Wall & 853 a 854 & Beryllium \\
\hline & Waster Heat & 854 a 856 & Copper \\
\hline & Shield Block & 856 a 898 & $60 \% \mathrm{SS} 304 \mathrm{~B} 7+40 \% \mathrm{H} 2 \mathrm{O}$ \\
\hline \multirow{3}{*}{ VV } & Wall & 898.5 a 904.5 & SS316L(N)IG \\
\hline & Filling & 904.5 a 967.5 & $84 \% \mathrm{SS} 316 \mathrm{~L}+16 \% \mathrm{H} 2 \mathrm{O}$ \\
\hline & Wall & 967.5 a 973.5 & SS316L(N)IG \\
\hline VVTS & Wall & 973.5 a 975.5 & SS316L(N)IG \\
\hline \multirow{3}{*}{ TFC } & Wall Box & 976 a 985.5 & SS316L(N)IG \\
\hline & $\begin{array}{l}\text { Superconductor and } \\
\text { insulator }\end{array}$ & 1085.5 a 1165.5 & $\begin{array}{l}45 \% \mathrm{Nb}_{3} \mathrm{Sn}+5 \% \mathrm{Al}_{2} \mathrm{O}_{3}+50 \% \text { Incoloy } \\
908\end{array}$ \\
\hline & Wall Box & 1165.5 a 1176 & SS316L(N)IG \\
\hline CRY & Wall & 1400 a 1410 & SS304L \\
\hline BSD & Wall & 1455 a 1655 & Concrete (2 type) \\
\hline
\end{tabular}

Table 2. Concrete compositions used

\begin{tabular}{c|c|c}
\hline Elements & $\begin{array}{c}\text { C-01 Composition } \\
\left(\rho=2.2505 \mathrm{~g}^{-3}\right)\end{array}$ & $\begin{array}{c}\text { C-02 Composition } \\
\left(\rho=2.43 \mathrm{~g} . c m^{-3}\right)\end{array}$ \\
\hline $\mathrm{H}$ & 0.4532 & 0.96 \\
\hline $\mathrm{B}$ & 0.07 & 2.90 \\
\hline $\mathrm{O}$ & 51.2597 & 51 \\
\hline $\mathrm{Na}$ & 1.1553 & - \\
\hline $\mathrm{Mg}$ & 0.3866 & 0.42 \\
\hline $\mathrm{Al}$ & 3.5548 & 0.79 \\
\hline $\mathrm{Si}$ & 35.9664 & 15.2 \\
\hline $\mathrm{K}$ & 1.4219 & - \\
\hline $\mathrm{Ca}$ & 4.3546 & 22.5 \\
\hline $\mathrm{Fe}$ & 1.3775 & 0.5 \\
\hline $\mathrm{C}$ & - & 5.31 \\
\hline $\mathrm{S}$ & - & 0.42 \\
\hline
\end{tabular}

\subsection{Other Adjusts and Output Solicitations}

The neutron and photon fluxes along of each cylindrical surface in the radial direction were requested. For a better understanding of the neutrons behavior in the different reactor systems, it was also requested data about the neutron and photon fluxes for different energy ranges. To calculate the dose rate due neutron and photons, it was used the conversion factor published by the International Commission on Radiological Protection (ICRP-21). The transport mode was set to photons and neutrons. The transport of electrons has not been considered because it does not increase the processing time. To obtain the statistical accuracy recommended, i.e., devia- tions of less than $10 \%$, it was necessary to monitor a large number of neutrons stories (approximately 106 primary neutrons).

\section{RESULTS AND ANALYSIS}

\subsection{Neutron Flux}

The neutron flux was determined for different energy ranges in all cylindrical surfaces along the radial machine direction from the plasma chamber to the outer surface of the bioshield. The mapping of the neutrons flux was performed to both types of concrete compositions used in this study. The evolution of neutron flux along the surface of the C-01 and C-02 components were plotted as can been verified in the Figures 3 and 4 , respectively.

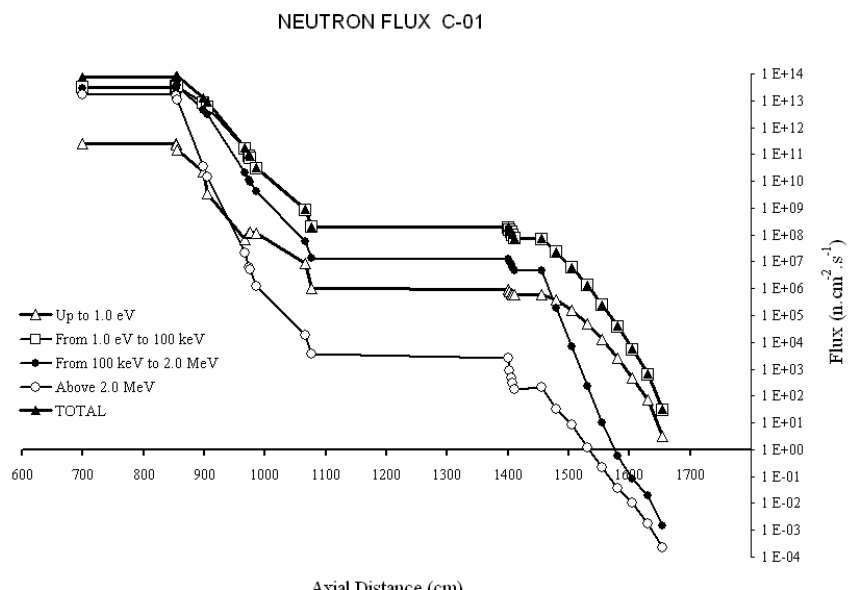

FIG. 3: Neutron flux along the radial way to concrete composition C-01

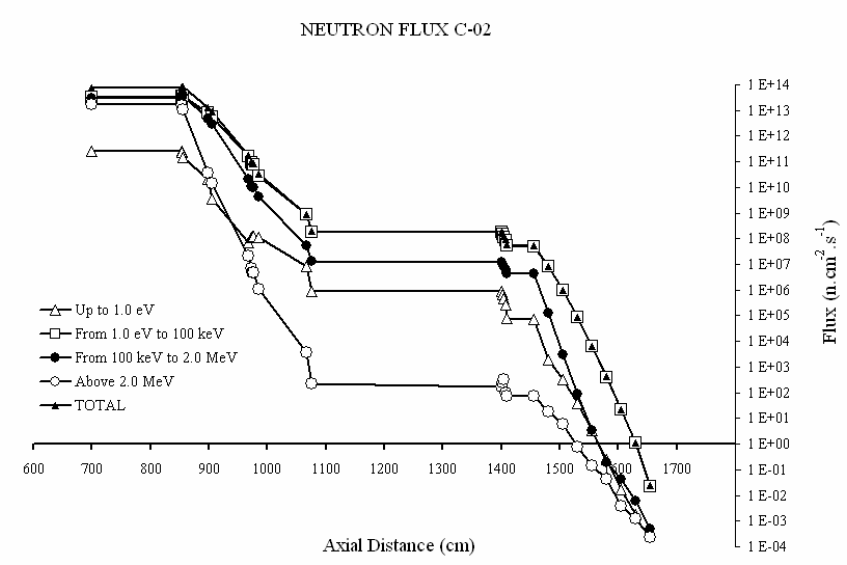

FIG. 4: Neutron flux along the radial way to concrete composition C-02 


\subsection{Dose Rate}

The results achieved for the dose rates due to neutrons and photons are shown in the Figures 5 and 6 for the concrete shield $\mathrm{C}-01$ and $\mathrm{C}-02$, respectively. Due to the high boron concentration presents in the concrete C-02 (2.9\% versus $0.07 \%$ ), the dose rate due neutrons had a sharp reduction of approximately 3 magnitude orders in comparison with the concrete $\mathrm{C}-01$. The highest density of the concrete C-02 $\left(2.43 \mathrm{~g} . \mathrm{cm}^{-3}\right.$ versus $2.25 \mathrm{~g} . \mathrm{cm}^{-3}$ to the $\left.\mathrm{C}-01\right)$ resulted in a reduction of about 1 magnitude order in a dose rate due to photons in comparison with the concrete $\mathrm{C}-01$.

The results for the total dose rate for shields with concrete C-01 and C-02 are compared in the Figure 7 and are in accordance with the expected behavior. As can be verified, the curves evolutions are practically identical up to arrive in the biological shield inlet point (at $\sim 1450 \mathrm{~cm}$ ). From this point, the particles are transported inside the concrete and the differences in the both compositions affect significantly the value of the dose rates. Clearly, the use of the concrete C-02 reduces the total dose rate for about one magnitude order in comparison with the concrete $\mathrm{C}-01$

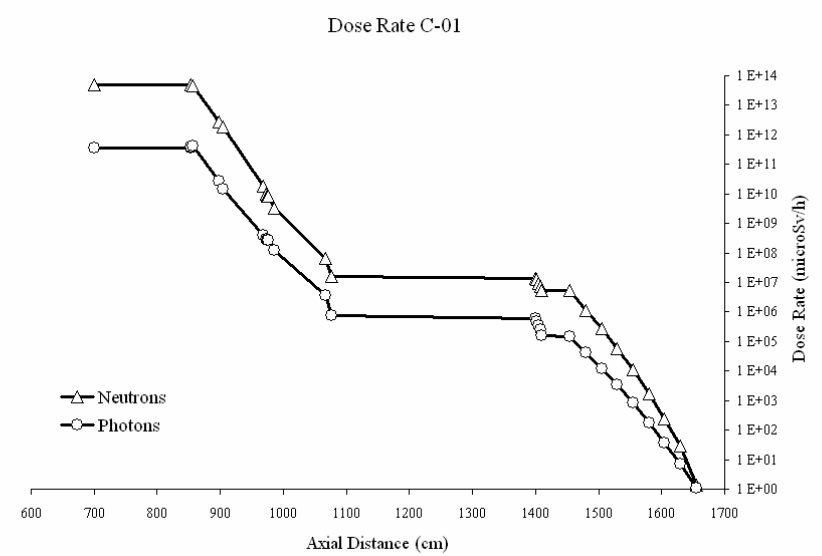

FIG. 5: Neutrons and photons dose rate along the radial way to concrete C-01

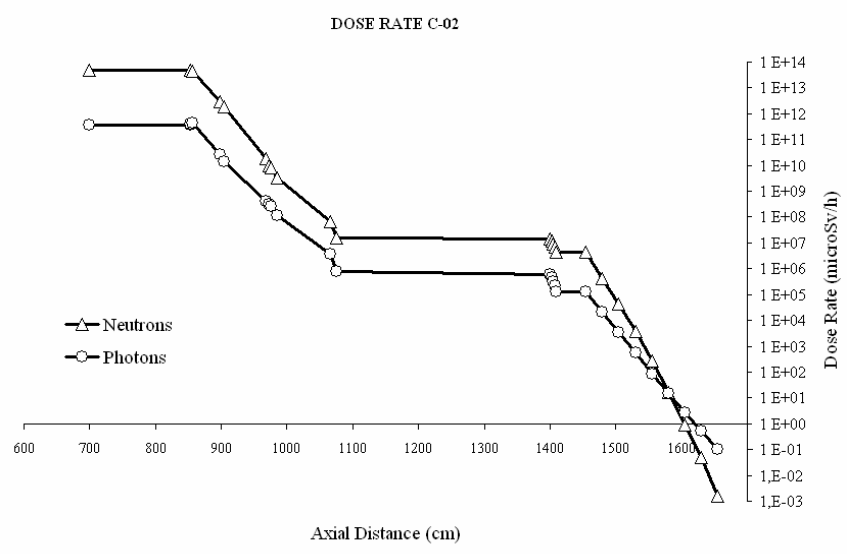

FIG. 6: Neutrons and photons dose rate along the radial way to concrete $\mathrm{C}-02$

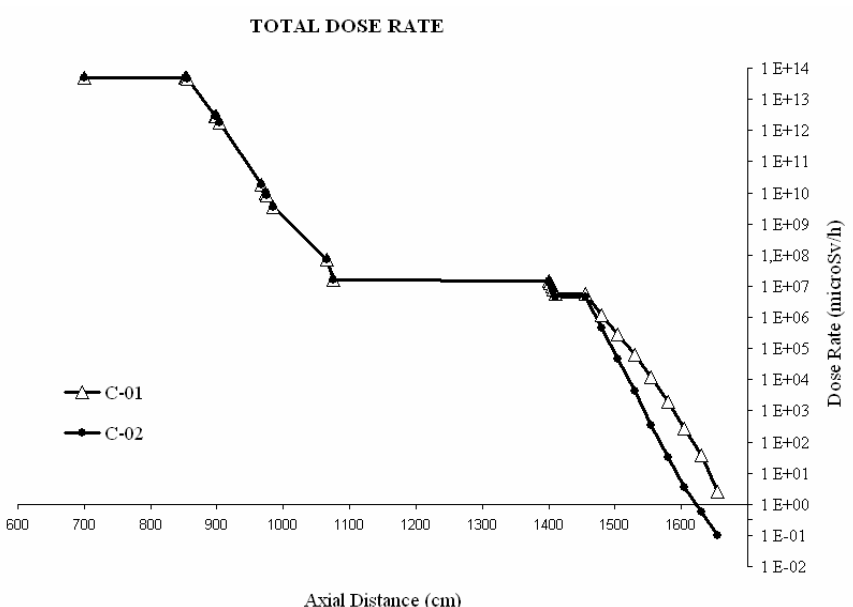

FIG. 7: Total dose rate along the radial way to concrete $\mathrm{C}-01$ and C-02

\section{CONCLUSION}

In the model used, the magnitude of the dose rate on the outside hall of bioshield during normal ITER operation can not be considered low in accordance with the result found in the simulation performed in this work, i.e., $1 \mu S v \cdot h^{-1}$. It is important to remember that the contributions due to the presence of slits between blanket modules and also the various holes in the cryostat and bioshield were not considered in the calculation. Moreover, the contributions related to the tritium dispersed in the air and the activated materials were not considered in this work. These simplifications certainly decrease a little the actual value that would be obtained if they were taken into account. It was determined that the dose rate inherent during the ITER operation is dominated by the photons contribution.

This work represents our initial efforts to simulate and estimate the dose rate along a tokamak using MCNP5. The results show good agreements with the references. The next step is to introduce a transmutation layer and simulate this 
system using MCNPX2.6.0, to analyze the depletion during an operation time.

\section{ACKNOWLEDGMENTS}

The authors are grateful to CNEN, CAPES, CNPq and FAPEMIG (Brazil) for the support.
[1] ITER Physics Basis Editor, el al,. "ITER Final Design Report", Nuclear Fusion, Vol 39, (1999).

[2] Y. Chen, Y. Wu, Q. Huang, "Monte Carlo based operational and shutdown dose rate calculations of HT-7U tokamak", Fusion Engineering and Design, Vol 70, pp. 155-162 (2002).

[3] S. Sandri, and L. D. Pace, "Collective dose at ITER feat", Fusion Engineering and Design, Vol. 63, pp.199-203 (2002).

[4] J. F. Briesmeister, MCNP - A General Monte Carlo N-Particle Transport Code, Version 5, Los Alamos National Laboratory, USA (2003).

[5] D. L. Aldama, A.Trkov, FENDL-2.1 Update of an evaluated nuclear data library for fusion applications, Summary documen- tation. (2004)

[6] J. Junker, A. Weller, Neutrons at W 7-X, Max-Planck Institut für Plasmaphysik, Germany (1998).

[7] V. Khripunovl, R. T. Santoro, H. Y. Khater, "Profit from Borating Concrete in the ITER Biological Shield", 17th IEEE/NPSS Symposium. (1997).

[8] J. P. Freidberg, Plasma Physics and Fusion Energy, Cambridge University Press, UK. (2007).

[9] D.B. Pelowitz, ed., "MCNPX User's Manual, Version 2.6.0, “ LA-CP-07-1473 (2008) 